\title{
Lumbar load attenuation for rotorcraft occupants using a design methodology for the seat impact energy-absorbing system
}

Research Article

\author{
Rasoul Moradi ${ }^{1 *}$, Hamid K. Beheshti², Hamid M. Lankarani ${ }^{3}$ \\ 1 TASS Americas, Livonia, Michigan, USA \\ 2 University of Isfahan, Isfahan, Iran \\ 3 Wichita State University, Wichita, Kansas, USA
}

Received 15 March 2012; accepted 09 June 2012

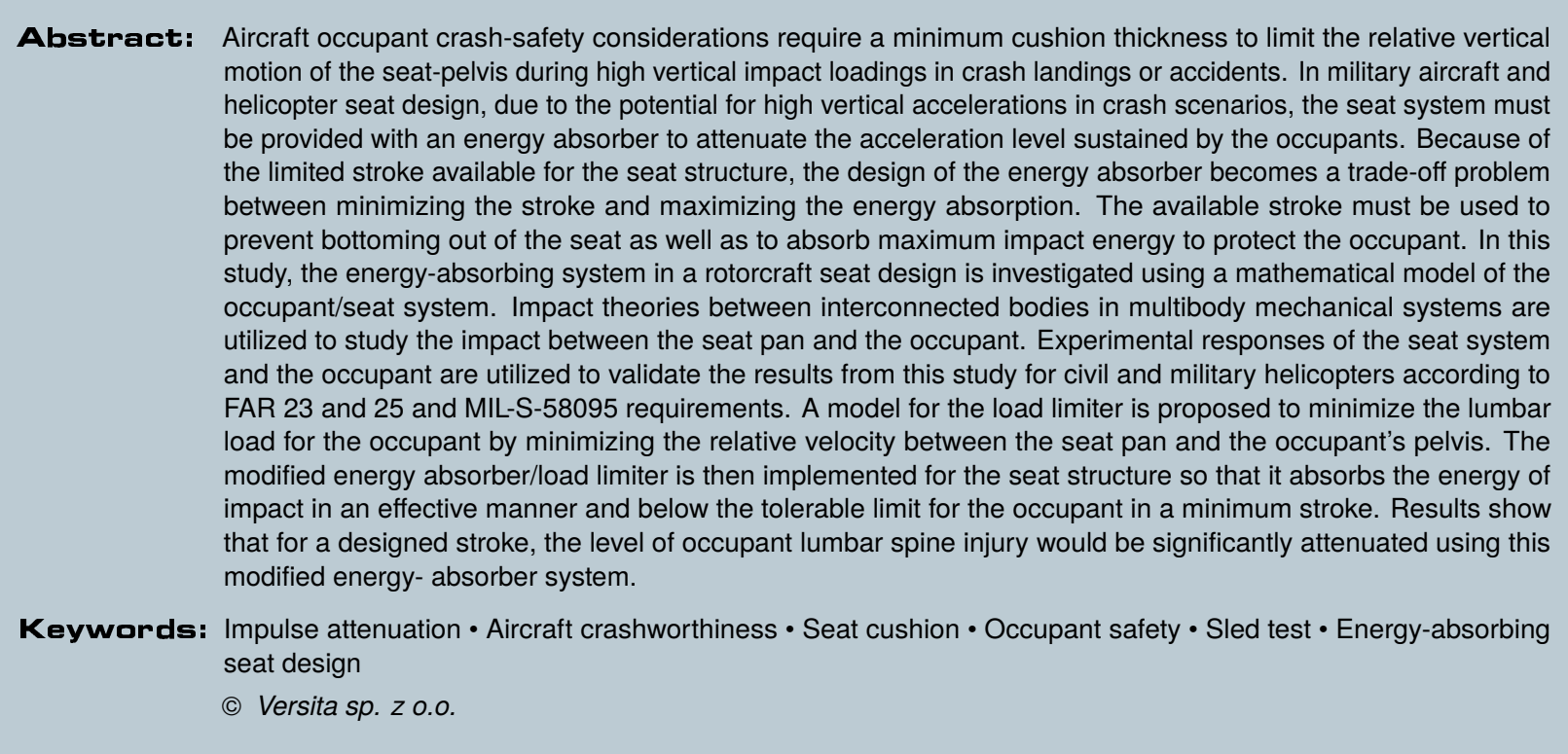

\section{Introduction}

The safety of occupants in aircraft and rotorcraft during any survivable crash has been a primary concern of the avi-

*E-mail: email@server.domain ation industry for many years [1-3]. The need for improved crashworthy seats in aircraft was initially established by the Aviation Crash Injury Research (AvCIR) Division of the Flight Safety Foundation during the late 1950s [4]. A limiting load imparted from the seat was necessary to improve the chance of survival and to minimize spinal fracture and risk of paraplegia. The major mode of injury in 
aircraft occupants as a result of vertical loading is in their lumbar or pelvic region [5]. Chandler [6] and Shanahan [7] developed a $6675 \mathrm{~N}$ (1500 lbf) lumbar load injury criterion. This criterion is now incorporated into Federal Aviation Regulation (FAR) Parts 23, 25, and 27 for rotary- and fixed-wing civil aircraft [8-10]. The military specification originally defined a spinal injury criterion in the form of seat pan acceleration, called a "load factor". Later, it became apparent that the seat pan acceleration criterion was potentially flawed as a reliable predictor of compressive spinal injury risk. Military seating specifications continue to use the measurement of seat pan acceleration instead of lumbar spine loading criteria [11], although it is generally accepted that tolerable lumbar loads for military aircraft applications are in the range of 8000-9790 N (1,800-2,200 lbf).

It is clear that a crashworthy seat shall be utilized only if it is comfortable, which has made the task of designing seats more difficult [5]. In the past, this has been accomplished by utilizing nets or extremely thick, soft cushions. It has been found that low spring rates of soft cushions allow large relative velocities to build up between the occupant and the seat pan during the imposition of impulsive loads, thus increasing the lumbar/pelvis load to the occupant. According to MIL-S-58095, the total thickness of the compressed cushion at the buttocks reference point should be minimized to $1 / 2-3 / 4$ in (13-19 mm) at 1 G load $[11,12]$. Payne [13] and Stech and Payne [14] demonstrated the increase in potential injury associated with the amplification effect of seat cushions on the dynamic response index (DRI), using a general model employing the single mass-spring-damper system to simulate the biomechanical response of the human body. Therefore, thoughtful integration of several mechanical components is required to produce an effective crashworthy energy-absorbing seat design.

In general, characteristics of the contact between occupant and seat determine whether there is significant dynamic overshoot within the body. While a slow rate of onset allows the body to come to the equilibrium-deformed configuration gradually, a rapid rate of onset effectively results in an impact between the seat and the body, creating high transient stresses and severe injuries. The soft cushion creates a plateau region in the load-deflection curve, which causes a multibody system to behave as if this region is a clearance between the seat pan and occupant. It is known that the existence of clearance in joints leads to load amplification, where the magnitude rises in proportion to the amount of clearance [15]. A dynamic compression index (DCl) was defined and utilized by $[16,17]$ as an inexpensive and time-conserving methodology for replacing seat cushions for aircraft seats. The $\mathrm{DCl}$ is the cushion compression distance available to the occupant before the

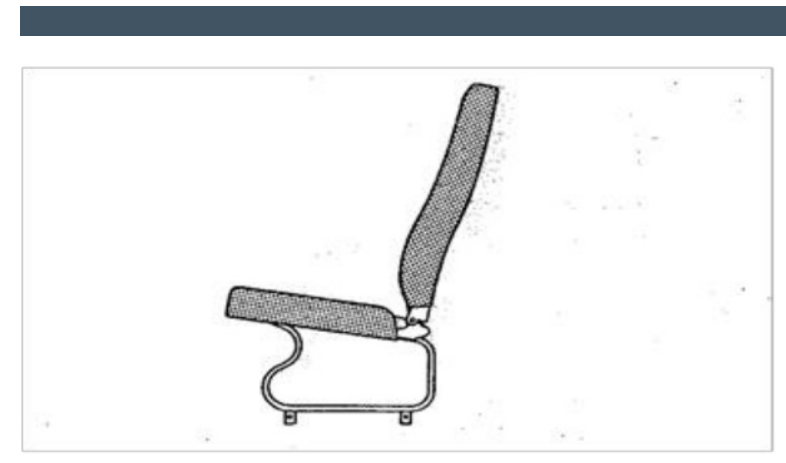

(a)

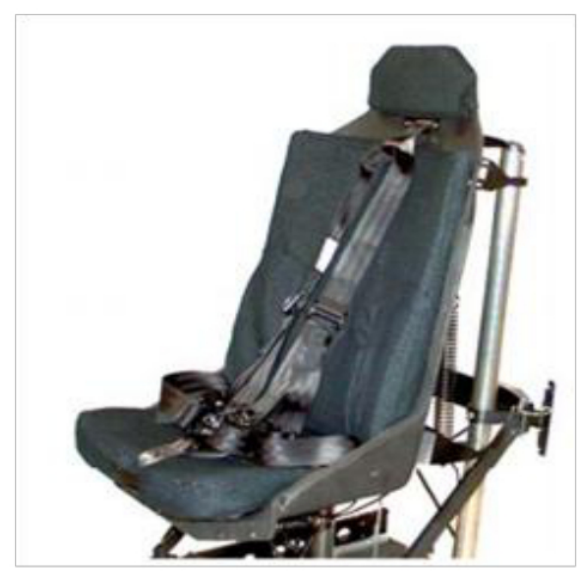

(b)

Figure 1. (a) seat with energy-absorbing legs [21], (b) cockpit seat with monolithic bucket [4].

cushion bottoms out during impact. A further study indicated that an increase in the $\mathrm{DCl}$ increased the lumbar load in a vertical impact crash scenario [18].

The energy-absorption capability of a seat structure must be considered in evaluating the dynamic strength of the seat. For high-peak impulses, to reduce the impact between the seat pan and occupant, the seat structure must possess sufficient energy-absorption capacity to reduce the occupant's relative velocity before it bottoms out. This seat structure capability is referred to as "load limit". The seat structure begins plastic deformation when the acceleration or load experienced by the occupant and seat reaches a level corresponding to the critical load limit, which corresponds to the human tolerable limit to provide the intended protective function. Attempts have been made to design seats that absorb impact energy for occupant protection without the use of an external energy absorber attached to the seat [19]. One such crew seat, shown in Figure 1(a), uses S-shaped tubular steel front legs designed to form plastic hinges to limit the load and provide energy absorption [20]. Although cost efficient, these seats are inefficient energy absorbers, and their performance is 
dependent upon the direction of impact. Such a concept has not been used in the design of successful military crew seats; it has only been used in general aviation and transport aircraft seats.

As seat technology was developing, many energyabsorbing mechanisms or concepts were proposed and adopted in operational systems. The desirable energy absorber should be as light and as small as possible with high specific energy absorption. The system should stroke at a constant force, resist loads in the opposite direction to the stroking (rebound), and be rate insensitive [12]. Today, most military aviation aircraft and rotorcraft are equipped with crashworthy seat systems, such as the one shown in Figure 1(b). Most of these seats use an energyabsorbing device that applies a constant load to decelerate the occupant and is referred to as a fixed-load energy absorber (FLEA). A manually adjustable or variable-load energy absorber (VLEA) was developed to produce the same level of protection for all sizes of occupants [4] Later on, the variable-profile energy absorber (VPEA) seat structure was developed to take advantage of the dynamic response of the occupant. The ultimate design is an automatic energy absorber (AEA), which provides the maximum amount of protection to a larger range of occupants [4].

It was determined in the early 1970s that the limit load or total dynamic stroking load $[22,23]$ of an energy-absorbing system had to be set to a lower value $(18 \mathrm{G})$ than originally thought. This was based on the observation of seat performance relative to tolerance data assembled by Eiband [24], in order to account for dynamic overshoot and to keep the load- duration environment within the human tolerable range [4]. Following extensive tests, it was recommended that the load factor should be retained at $14.5 \mathrm{G}$ for U.S. army aircraft seats, and between $11 \mathrm{G}$ and $13 \mathrm{G}$ for commercial and light aircraft, by using the energy-absorber system to protect the spine [21-23, 25]. The $14.5 \mathrm{G}$ design criterion considers the dynamic response of the seat and occupant. In their testing, the standard bottom cushion used in a UH-60A crew-seat bucket was utilized. The load factor of $14.5 \mathrm{G}$ was defined based on the maximum load sustained by the occupant, which was influenced by the cushion's characteristics. If a rigid seat had been used in the tests, the load factor could have been higher due to elimination of the cushion compliance, and the occupant pelvic compliance was the only contributing factor to the load limit.

Reducing the energy-absorber load limit to a low value to prevent decelerative spinal injuries may actually increase the spinal injury rate, since in a greater number of accidents, the seat bottoms out, increasing the likelihood of spinal injury [4]. The desirability of certified seats with the shortest possible stroke is a concern, which encourages

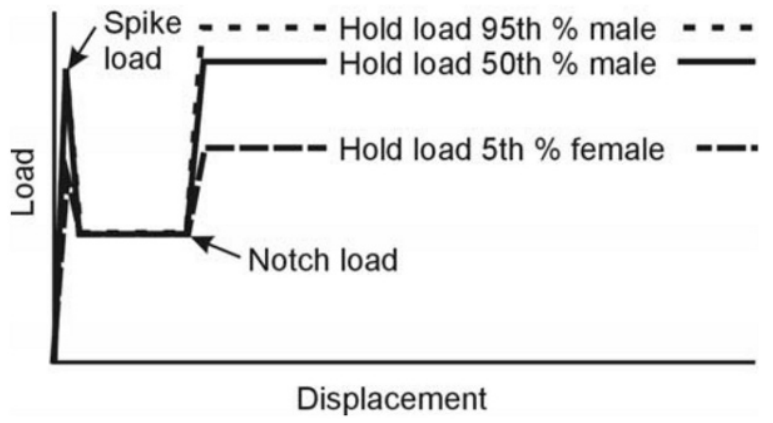

Figure 2. Stroke characteristics of variable-profile energy absorber (VPEA) [4].

seat suppliers to be innovative and to develop seats with energy-absorbing systems that require short strokes [4].

In a study by Carr and Phillips, it was concluded that an energy absorber can be designed such that it takes advantage of the dynamic response of the human body [26]. A notched load- stroke profile was suggested so that it compressed the springs in the human body more quickly by imposing a high initial load spike, as shown in Figure 2. Then it would lower the load rapidly to minimize the occupant's spine load overshoot as the body springs loaded up and bottomed out. The energy-absorbing load would then be increased again slowly to a plateau, which could be sustained with the body springs loaded and compressed for the rest of the stroke.

If the energy-absorbing system is to provide only one load setting, then that load should be sized for the effective weight of $50^{\text {th }}$-percentile occupants to ensure a tolerable stroke for the majority of occupants while not exceeding the stroke limitations of the seats [4]. Then $50^{\text {th }}$ - percentile occupants will be the only occupants decelerated at the load limit selected as the tolerable limit. Lighter occupants will be decelerated at a higher rate, and heavier occupants will be decelerated a lower rate than will the $50^{\text {th }}$-percentile occupants.

Crew seats should be designed to stroke a minimum distance of $30 \mathrm{~cm}$ (12 in) when the seat is in the lowest position of the adjustment range [4]. This distance is needed to absorb the residual energy associated with the vertical design pulse. Even with a $30 \mathrm{~cm}$ stroke, the heavier occupants in more severe impact crashes will exhaust the available stroke distance and bottom out.

As observed, a number of studies have addressed the design of the energy-absorbing system for rotorcraft seats. The objective of this study is to build on this knowledge and expand the development of different energy-absorbing systems for rotorcraft seats based on the examination of load-limit curves and corresponding strokes. This is done using a combination of simplified mathematical modeling of 


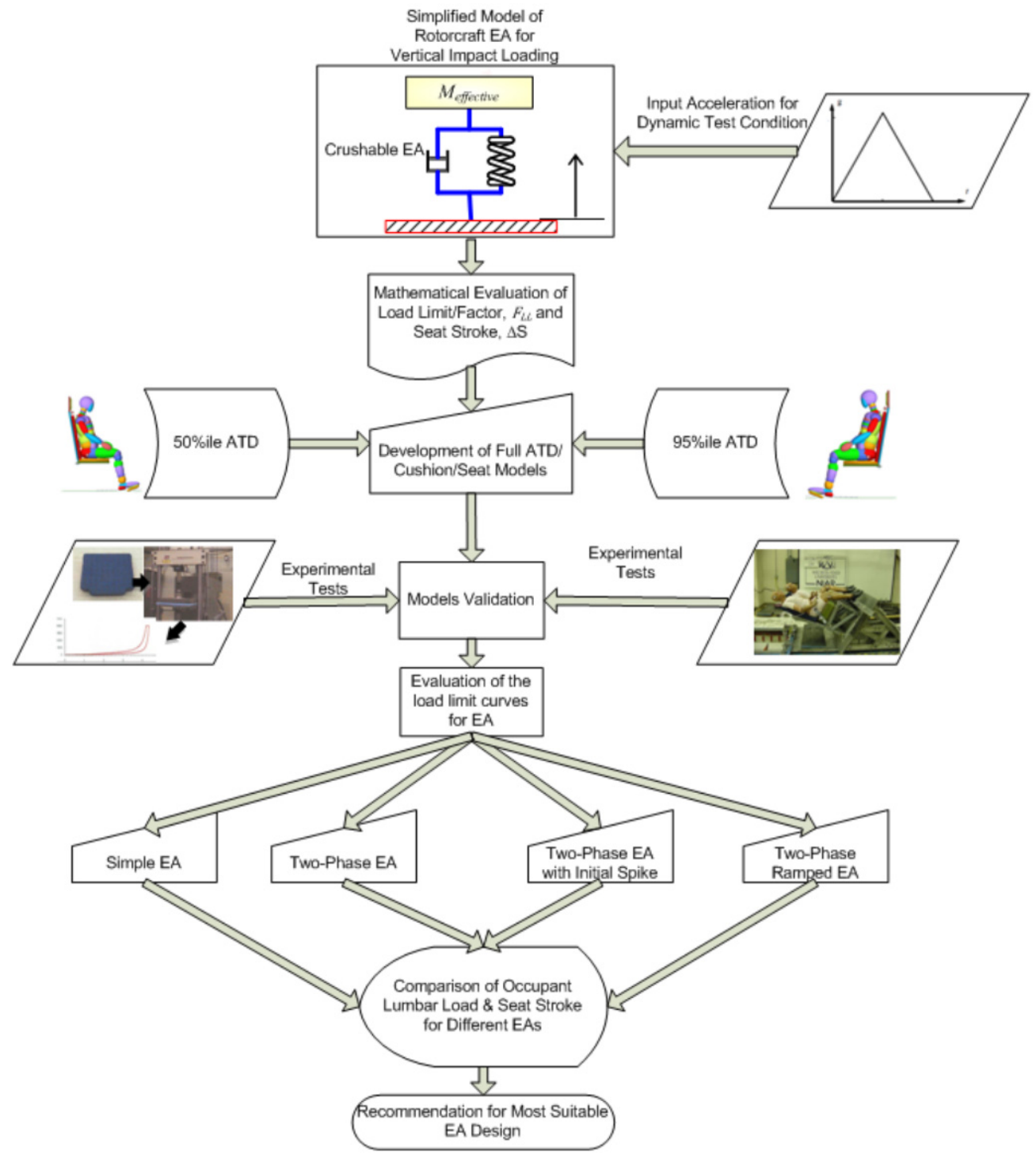

Figure 3. Methodology utilized in this study to design seat energy-absorbing system.

the seat energy-absorbing system and occupant; detailed biodynamic modeling of the seat cushion and occupant; experimental testing and model validation; and, finally, a parametric study to evaluate the different designs.

\section{Methodology}

In this study, based on the kinematics of a seat and its occupant in a vertical impact, first the seat stroke and stroking stop time are evaluated in terms of the energy-absorber load factor. Due to the existence of several variables in the system and the efficiency of the load limiter, the evaluated seat stroke might not correlate entirely with experimental tests but could still be a good factor in seat-structure design. Then, a computational model of an aircraft seat and occupant is developed in MADYMO, and a set of experiments are utilized to validate the model. An industry seat cushion is tested to obtain the load-deformation curve under a dynamic loading condition. A Federal Aviation Administration (FAA) Hybrid-III 50 ${ }^{\text {th }}$-percentile anthropomorphic test device (ATD) model is used as an occupant on a seat-system model. The cushion load-deformation results are implemented in the model, and the occupant/seat model is subjected to a vertical impact test condition to validate the computational model. The seat energy absorber is then augmented to the occupant/seat model and validated with experimental results under different test conditions 


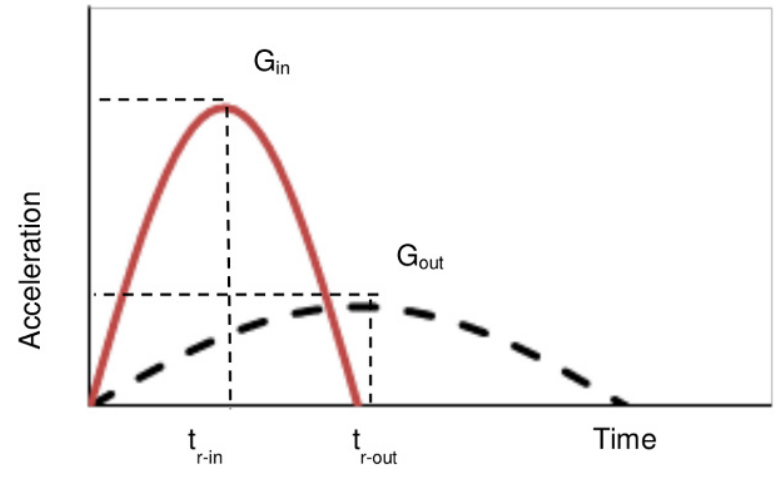

Figure 4. Typical input-output in shock mitigation system.

$[18,27]$. Different energy-absorber load-limiting characteristics are then evaluated to identify the most suitable design concepts for the energy absorber. The energy- absorber design iterations are examined to keep the occupant lumbar load below the tolerable limit and to maximize the seat stroke. Such a design would be a great benefit for military rotorcraft, which have limited room underneath the seats, in order to utilize the maximum energy-absorbing capability of the seat system. The design of the seat energy absorber is investigated in this study based on a mid-size male aviator. However, the idea can be extended to all occupant sizes, and an appropriate energy absorber can be designed. Figure 3 outlines the methodology utilized to design the seat energy absorber in this study. The steps in the design methodology are described in detail in the next section.

\subsection{Mathematical evaluation of load limits}

Impact loading is different from static loading where a state of equilibrium is reached. Both objects involved in an impact can be subjected to elastic and/or plastic deformations [28]. During impact, some energy is stored through elastic strain, stress wave propagation, plastic deformation, material dampening, or other phenomenon such as sound or heat [29]. The impact energy that a component can elastically absorb is a function of its modulus of resilience times the components' volume. The superior modulus of resilience is the reason that rubber is used as a shock-mitigation material.

In the design of a shock-mitigation system, the goal is to spread out the input impulse over time, thereby reducing its magnitude to acceptable levels for the system being protected. In other words, the input pulse is absorbed by the shock-arresting device, and the shock energy is released over a broader time, lowering the magnitude of the pulse to the protected system, as shown in Figure 4.
From the magnitude and time duration of the input pulse, the change in velocity $\Delta V$ of the impactor can be determined. The output response Gout from the shock mitigation device should not exceed the fragility or tolerable limit of the component or system being protected. Then, the natural frequency $f_{n}$, representing the inverse of the time frame for which the shock pulse will be released, can be determined as

$$
G_{\text {out }}=\frac{2 \pi f_{n} \Delta V}{g}
$$

Based on the mass of the system to be protected $m$ and the required frequency $f_{n}$, a shock mitigation material stiffness $K$ can be selected as

$$
\left(2 \pi f_{n}\right)^{2}=\frac{K}{m}
$$

to reduce the shock pulse. The most efficient process for limiting loads is the one that absorbs or dissipates energy rather than the one that stores it [4]. Plastic deformation of material, primarily metals, results in a reasonably efficient energy-absorbing process. However, sizing components for plastic impacts are much more difficult. As a first-cut approximation in sizing a component for plastic impact, the sum of the crush force $\bar{F}$ or moment $\bar{M}$ over its plastic displacement $X$ or $\theta$ can be equated to the impact energy as

$$
\frac{1}{2} m \Delta V^{2}=\frac{1}{2} m V^{2}\left(1-e^{2}\right)=\bar{F} X \text { or } \bar{M} \theta
$$

where, $m$ is the mass of the impactor, and $e$ is a coefficient of restitution representing the energy absorbed in the impact. The coefficient of restitution depends on materials and geometries of bodies at impact, and impact velocity $(0 \leq e \leq 1)$. As observed from Equation (3), for the same energy, the larger the crush distance, the lower the average load on the mass.

Each seat system for military crew and troop, and civil rotorcraft occupancy must successfully complete dynamic tests or be demonstrated by rational analysis supported by dynamic tests, in accordance with specific conditions defined in MIL-S-58095(AV), MIL-S- 85510(AS), and SAE, AS8049 respectively $[11,30,31]$. Federal performance requirements for civil helicopters are established in the U.S. Code of Federal Regulations (CFR), Title 14, Parts 27 and $29[9,10]$. These tests must be conducted with an occupant simulated by an ATD, defined in CFR 49, Part 572, Subpart B, commonly known as Hybrid-II 50 $0^{\text {th }}$-percentile dummy, or an FAA-approved equivalent such as the FAA Hybrid-III dummy, with a nominal weight of $77 \mathrm{~kg}$ (170 pounds) and seated in the normal upright position [32]. The seating configurations and deceleration-time pulse developed for the design and test of the seat system are 


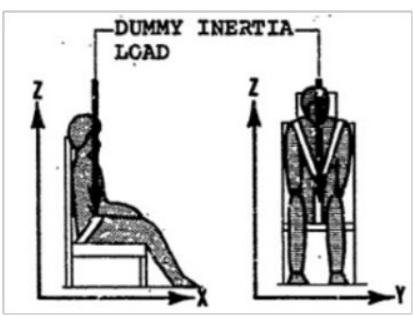

(a) Downward load [31]

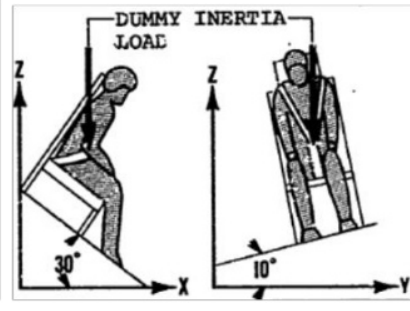

(b) Downward, forward, and lateral loads [31].

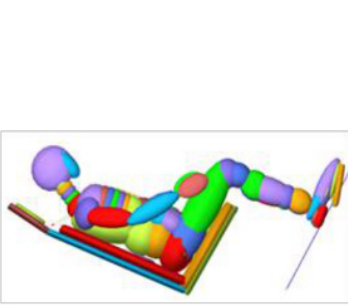

(c) FAR 23, 25, 27 and 29 test configuration.

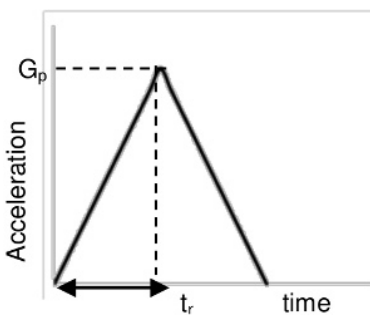

(d) Downward acceleration pulse.

Figure 5. Military and FAR seat dynamic test configurations and acceleration input.

shown in Figure 5, where $t_{r}$ is the acceleration rise time, and $G_{p}$ is the peak acceleration.

The seat energy-absorbing stroke simply lengthens the stopping distance of the occupant. The seat may continue to stroke until the kinetic energy of the seat occupant has been exhausted. By defining a time-step function at time $t_{r}$ as

$$
<t-t_{r}>=\left\{\begin{array}{lll}
0 & \text { if } & t<t_{r} \\
t-t_{r} & \text { if } & t>t_{r}
\end{array}\right.
$$

the input acceleration $\ddot{S}$ and the corresponding velocity and displacement $\dot{S}_{t}$ and $S(t)$ in the vertical (lumbar axis) direction can be calculated by direct integration of the acceleration function, respectively, as

$$
\begin{array}{rl}
\ddot{S}(t)=- & {\left[\left(\frac{G_{p}}{t_{r}}\right) t-2\left(\frac{G_{p}}{t_{r}}\right)<t-t_{r}>\right.} \\
+ & \left.\left(\frac{G_{p}}{t_{r}}\right)<t-2 t_{r}>\right] \\
\dot{S}(t)= & V_{0}-\frac{G_{p} t^{2}}{2 t_{r}}+\frac{G_{p}<t-t_{r}>^{2}}{t_{r}} \\
& +\left(\frac{G_{p}}{2 t_{r}}\right)<t-2 t_{r}>^{2} \\
S(t)=V_{0} & t-\frac{G_{p} t^{3}}{6 t_{r}}+\left(G_{p} / 3 t_{r}\right)<t-t_{r}>^{3} \\
+ & \left(G_{p} / 6 t_{r}\right)<t-2 t_{r}>^{3}
\end{array}
$$

where $V_{0}$ is the system initial velocity. The equilibrium condition at time $2 t_{r}$ yields

$$
V_{0}=G_{p} t_{r}
$$

Then,

$$
S\left(2 t_{r}\right)=G_{p} t_{r}^{2}
$$

For the seat/occupant system, due to the load-limiter effect at time $t_{l}$ which corresponds to acceleration level of $G_{l}$, the seat vertical acceleration $\ddot{S}_{s}(t)$ would be constant until the energy absorber stops stroking at time $t_{f}$. Using the same method as above, the seat acceleration, velocity, and displacement functions can be written, respectively, as

$$
\begin{gathered}
\ddot{S}_{s}(t)=-\left[\left(\frac{G_{p}}{t_{r}}\right) t-\left(\frac{G_{p}}{t_{r}}\right)<t-t_{l}>\right. \\
\left.-\left(\ddot{S}+G_{l}\right)<t-t_{f}>^{0}\right] \\
\dot{S}_{s}(t)=V_{0}-\frac{G_{p} t^{2}}{2 t_{r}}+\frac{G_{p}}{2 t_{r}}<t-t_{l}>^{2} \\
+G_{l}<t-t_{f}>+\dot{S}(t)<t-t_{f}>^{0} \\
+\frac{G_{l}<t-t_{f}>^{2}}{2}+S(t)<t-t_{f}>^{0} \\
S_{s}(t)=V_{0} t-\frac{G_{p} t^{3}}{6 t_{r}}+\frac{G_{p}<t-t_{l}>^{3}}{6 t_{r}} \\
+\frac{G^{\prime}}{2}
\end{gathered}
$$

For a seat/occupant effective mass of $M_{\text {eff }}$, the force applied to the seat, or the load-limiter load $F_{s}(t)$ or $F_{L L}(t)$, can be calculated as

$$
F_{s}(t)=F_{L L}(t)=M e_{f f} \ddot{S}_{s}(t)
$$

Figure 6 shows the acceleration, velocity, and displacement of both the floor and the occupant/seat pan in the presence of a load-limiting energy absorber for two cases: low and high load-limit factors. The area between the velocity-time graphs for the floor and the seat pan for each case equals the energy-absorber stroke, which can be evaluated from the above equations for the cases $t_{f}>2 t_{r}$ and $t_{f}<2 t_{r}$, respectively. 


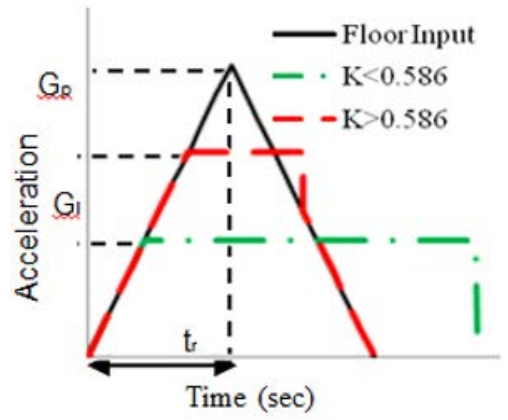

(a)

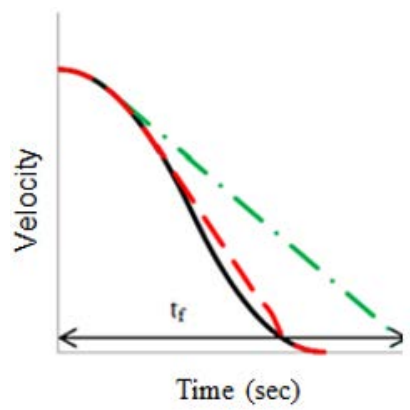

(b)

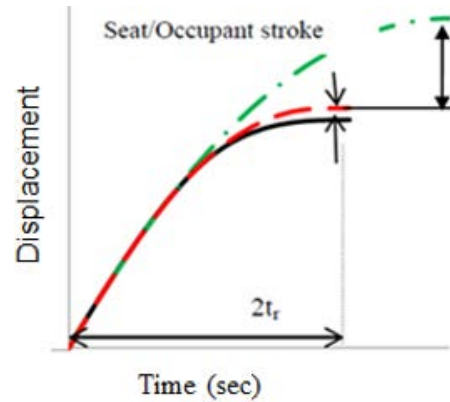

(c)

Figure 6. (a) deceleration, (b) velocity, and (c) displacement versus time for airframe and seat pan for $K<0.586$ and $K>0.586$.

Let $\frac{G_{l}}{G_{p}}=\frac{t_{l}}{t_{r}}=K$. Then the determination of whether the stroking stop-time is greater or less than time $2 t_{r}$ can be made by equating velocities for the floor and the seat pan at time $t_{f}$ as

$$
t_{f}=2.414(\sqrt{2}-K) t_{r}
$$

From Equation (14), for $t_{f}=2 t_{r}$, we obtain $K=0.586$ which means that both seat pan and floor stop at the same time. For $K<0.586$ or $t_{f}>2 t_{r}$, the seat structure keeps stroking after floor stops, then we obtain:

$$
\left\{\begin{array}{l}
S(t f)=G_{p} t_{r}^{2} \\
S_{s}\left(t_{r}\right)=V_{0} t_{f}-\frac{G_{p} t_{f}^{3}}{6 t_{r}}+\frac{G_{p}<t_{f}-t_{l}>^{3}}{6 t_{r}}
\end{array}\right.
$$

Subtracting distances for each case yields

$$
\Delta S=G_{p} t_{r}^{2}\left(\frac{1}{2 K}+\frac{K}{2}-\frac{K^{3}}{24}-1\right)
$$

For $K \geq 0.586$ or $t_{f}<2 t_{r}$,

$$
\left\{\begin{array}{l}
S\left(t_{f}\right)=V_{0} t_{f}-\frac{G_{p} t_{f}^{3}}{6 t_{r}}+\left(\frac{G_{p}}{3 t_{r}}\right)<t_{f}-t_{r}>^{3} \\
S_{s}\left(t_{f}\right)=V_{0} t_{f}-\frac{G_{p} t_{f}^{3}}{6 t_{r}}+\frac{G_{p}<t_{f}-t_{l}>^{3}}{6 t_{r}}
\end{array}\right.
$$

Then the seat structure stops stroking before the floor stops. Subtracting the distances yields:

$$
\Delta S=g_{p} t_{r}^{2}\left(5.093 K^{3}-12.36 K^{2}+9.449 K-2.178\right)
$$

This has been illustrated in Figure 6. As it can be seen, the occupant's velocity is reduced at a lower rate than that of the seat frame, and the occupant has stroked at a larger distance than the floor.
As the result of ignoring the importance of impact direction on the level of seat acceleration, the concept of the load-limit factor has created some confusion in stroke calculations. The load-limit factor is not necessarily the seat-acceleration level, unless the direction of the dynamic acceleration is horizontal. Examples of the vertical acceleration test and non-vertical acceleration test are provided here to show the differences in the calculation for $C_{L}$. As an example, for the model subjected to acceleration according to the MIL-S-58095 vertical test $\left(t_{r}=0.027 \mathrm{sec}\right.$, $V_{0}=128 \mathrm{~m} / \mathrm{sec}\left(42 \mathrm{ft} / \mathrm{sec}, G_{p}=48 \mathrm{G}\right)$ with a static loadlimit factor of $14.5 \mathrm{G}$, the seat-base acceleration level and corresponding stroke can be evaluated, respectively, as

$$
\begin{gathered}
F_{L L}-m G=m G_{L} ; \quad \text { then } \quad G_{L}=13.5 \mathrm{G} \\
K=0.281, \quad t_{f}=2.73 t_{r}, \quad \Delta S=31.5 \mathrm{~cm}(12.4 \mathrm{in})
\end{gathered}
$$

Calculation of the stroke for the seat acceleration limit of 14.5 G yields erroneous results as

$$
K=0.302, \quad t_{f}=2.685 t_{r}, \quad \Delta S=27.7 \mathrm{~cm}(10.9 \mathrm{in})
$$

The preceding calculations for seat stroke are based on ideal energy absorber (elastic-perfect plastic material) and may not be reached in a practical test. Usually, results from the above equations should be considered the minimum stroke distance required, and allowance for additional stroke should be provided. In a very rough calculation, using a simple linear dynamic model of the $50^{\text {th }}$-percentile occupant, application of the load limit of $14.5 \mathrm{G}$ results in a lumbar load of $F_{\text {Lumb }}=M_{2} G_{l}=4830 \mathrm{~N}$, where $M_{1}=43 \mathrm{~kg}$ for the lower body part, and $M_{2}=34 \mathrm{~kg}$ for the upper body part [33].

Based on the principles of rigid-body dynamics, in order to protect a mid-size occupant spine for the axial load of less than 6675 N (1500 lbf), a static load-limit factor of 
20 G can be applied to the system, which is still below the Eiband limit for tolerable acceleration. The maximum lumbar load at a load-limit factor of $14.5 \mathrm{G}$ is far beyond the results of rigid-body dynamics. The compliance of the pelvis area along with that of the seat cushion initiates a relative velocity between the occupant and the seat pan. This relative velocity provides an impact between the seat bucket and occupant, and amplifies the inertial load applied from the accelerated floor (seat pan). Obviously, reducing the cushion compliance mitigates the overshoot, at the expense of reducing the comfort level. Elimination of the spine load overshoot is not possible due to a certain compliance interaction of the pelvis with the rigid seat. However, if the relative velocity is decreased before the cushion/pelvis bottoms out, then the overshoot would be reduced. Thus, the load limit could be increased to a higher level, still keeping the lumbar load at the required level. This could be achieved using a load limiter with a certain constant load level for a short period of time and then increasing it gradually to a higher level. The benefit of this load limiter would be to minimize the stroke required for a certain load-limit factor. In another words, with the same stroke designed for a seat, the occupant's lumbar spine load level would be significantly attenuated by reducing the initial load-limit factor and increasing it to a higher level.

For purposes of the load-limit calculation, the effective weight in the vertical direction of a seated occupant is assumed to be approximately 80 percent of the occupant's total weight, because the lower extremities are partially supported by the floor [27]. Assuming a $27 \mathrm{~kg}$ (60 lb) movable seat mass (and portions of a crew's clothing, helmet, and boots), the total effective masses that the load limit system must be designed for are $75.5 \mathrm{~kg}$ (166.7 lb), $88.8 \mathrm{~kg}$ (196 lb), and $104 \mathrm{~kg}$ (229.4 lb), for $5^{\text {th }}$-percentile, 50 $0^{\text {th }}$ percentile, and $95^{\text {th }}$-percentile aviators, respectively. The load limit $F_{L L}$ for a $14.5 \mathrm{G}$ load-limit factor is calculated as

$$
F_{L L}=G_{L} W_{e f f}
$$

A load limit of $F_{L L}=12642 \mathrm{~N}(2,842 \mathrm{lb})$ is calculated for a $50^{\text {th }}$-percentile male aviator. The load factors for the $95^{\text {th }}$-percentile and $5^{\text {th }}$-percentile aviators are then calculated as

$$
\begin{gathered}
G_{L}-95^{\text {th }}=F_{L L} /\left(W_{\text {eff }}-95 \% \text { ile }\right)=12.4 \\
G_{L}-5^{\text {th }}=F_{L L} /\left(W_{\text {eff }}-5 \% \text { ile }\right)=17
\end{gathered}
$$

This means that with the same load limit factor of $14.5 \mathrm{G}$, the heavier occupant experiences a lower lumbar load, and a smaller-size occupant sustains a higher lumbar load, provided that the required stroke is available for the heavier occupant.

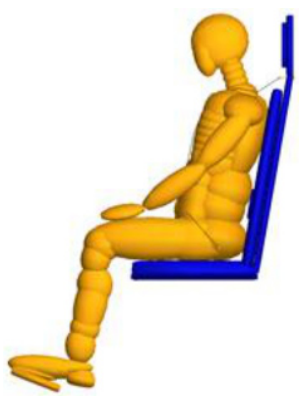

(a)

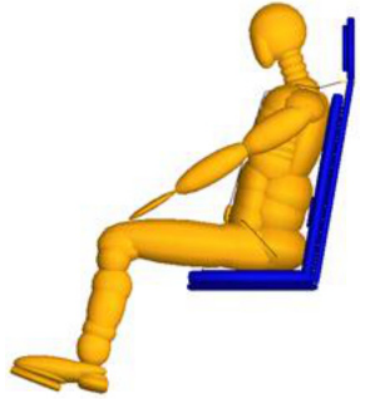

(b)
Figure 7. MADYMO models of seat, cushion, ATD, and seat belt for vertical test configuration for (a) $50^{\text {th }}$-percentile dummy and (b) $95^{\text {th }}$-percentile dummy.

Table 1. Typical cushion properties for crew seat utilized in this study [27].

\begin{tabular}{lcc}
\hline $\begin{array}{l}\text { Load } \\
N(\mathrm{lb})\end{array}$ & $\begin{array}{c}\text { Deformation } \\
\mathrm{mm}(\mathrm{in})\end{array}$ & $\begin{array}{c}\text { Unloading Rate } \\
\mathrm{N} / \mathrm{mm}(\mathrm{lb} / \mathrm{in})\end{array}$ \\
\hline \hline 0 & 0 & \\
$396(89)$ & $2.54(0.1)$ & $140(800)$ \\
$2781(625)$ & $17.8(0.7)$ & $140(800)$ \\
$10145(2280)$ & $27.9(1.10)$ & $175(1000)$ \\
$19579(4400)$ & $31.7(1.25)$ & $350(2000)$ \\
\hline
\end{tabular}

\subsection{Full ATD/seat/cushion model develop- ment and validation}

A MADYMO [34] model was developed and employed in this study to evaluate the lumbar load for the crash test. Planes and ellipsoids were used to create models of the seat pan, seat back, sled, feet steps, and seat cushion. The FAA Hybrid-III 50 $0^{\text {th }}$-percentile ATD was utilized as the occupant. A five-point harness configuration, which is primarily utilized in the aviation industry for crew seats, was utilized to restrain the occupant on the seat. Figure 7 depicts the entire MADYMO model including the seat system, sled, and dummy created for this crash simulation. Effort was taken to create the model as comparable as possible to real-world sled tests. The required deceleration pulses were applied to the system using a translational joint motion in the vertical direction. The belt was allowed to slip on the dummy by considering a typical friction coefficient of 0.2 between each segment and the body. A typical friction coefficient of 0.2 between the occupant and the seat back and seat cushion, and a value of 0.3 between the feet and the base was utilized in the model. For validation purposes, a $95^{\text {th }}$-percentile aviator male model was also developed using MADYSCALE [34].

The compliance of the cushion was implemented by using the data obtained from an experimental test for a 5-in 


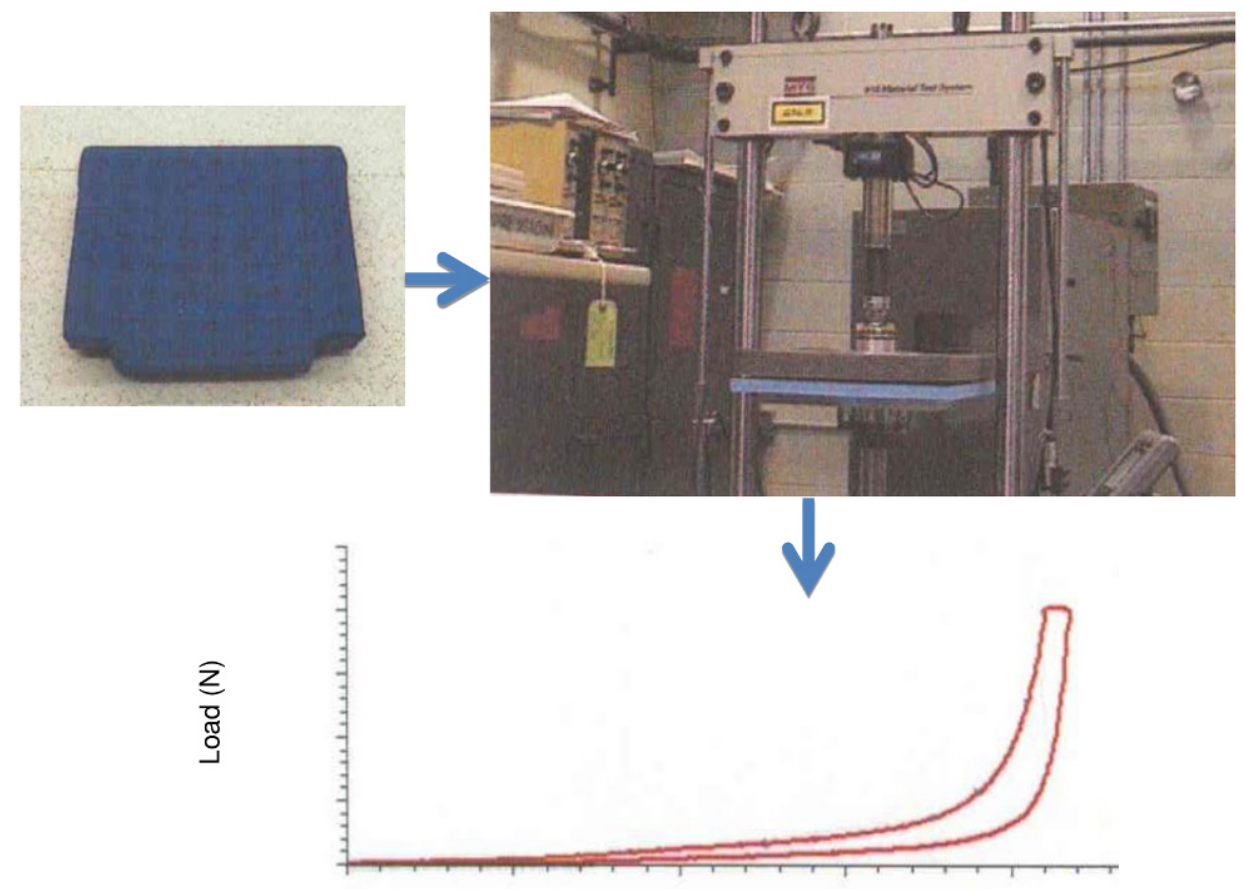

Displacement $(\mathrm{mm})$

Figure 8. Experimental setup to generate load-deflection curve of an industry seat cushion.

industry cushion, as shown in Figure 8, and also from the literature (Table 1) for a 1.56-in-thick layer of typical polyethylene slow-rebound foam [27]. Seating geometry was applied according to MIL-STD-1333A for $50^{\text {th }}$-and $95^{\text {th }}$-percentile male aviators [35]. The energy-absorber system was modeled using a translational joint with a suggested restraint between the floor and bucket back as the system load limiter. To reach the equilibrium condition, the model was run for a short period of time before application of the vertical impulse.

The model was validated for a rigid seat and a seat with an industry cushion of 5-in thickness under Part 25 and Part 23 dynamic Test-I conditions, respectively. The experimental test results conducted by the NIAR [18] are shown in Figure 9. The lumbar load responses of an occupant on a rigid metal seat and the seat covered by a low rate-sensitive industry cushion are shown in Figure 10.

Comparing the lumbar load from the rigid-seat sled test and simulation from this study shows quite reasonable agreement within the range of $5 \%$ at the peak value and rise time. The peak lumbar load also correlates with the linear analysis calculation for a rigid seat and dummy, for which the lumbar load is $4830 \mathrm{~N}$ (1087 lbf). Due to the difference in the belt system from this simulation, which is a five-point belt system equipped with retractor compared to a simple two- point lap belt utilized in the sled test,

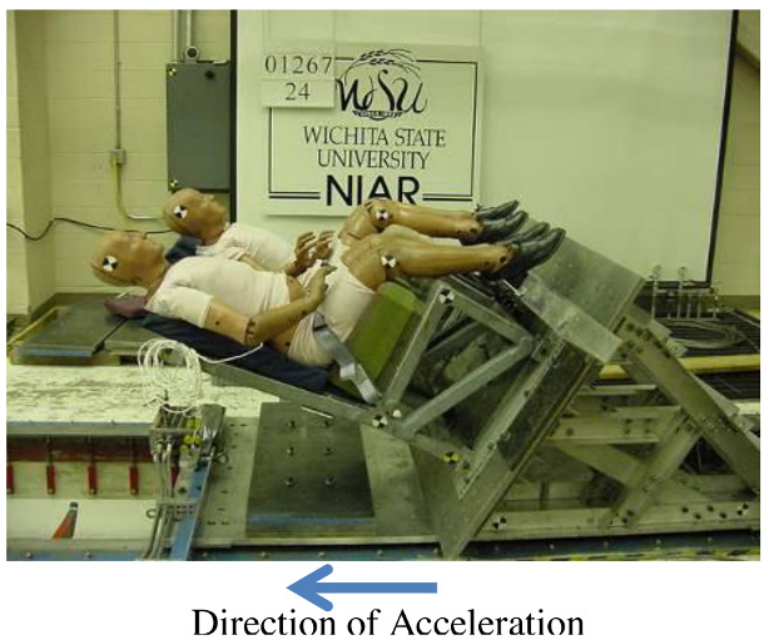

Figure 9. Full-scale dynamic sled test for certification of seat cushions.

the rebound of the occupant causes a small tension in the lumbar load. Also, the occupant's upper body in the test results shows more rotation compared to the shoulderbelted occupant in the simulation results, which in turn attenuate the lumbar load in the sled test. Differences between the peak lumbar load and rise time could also be 

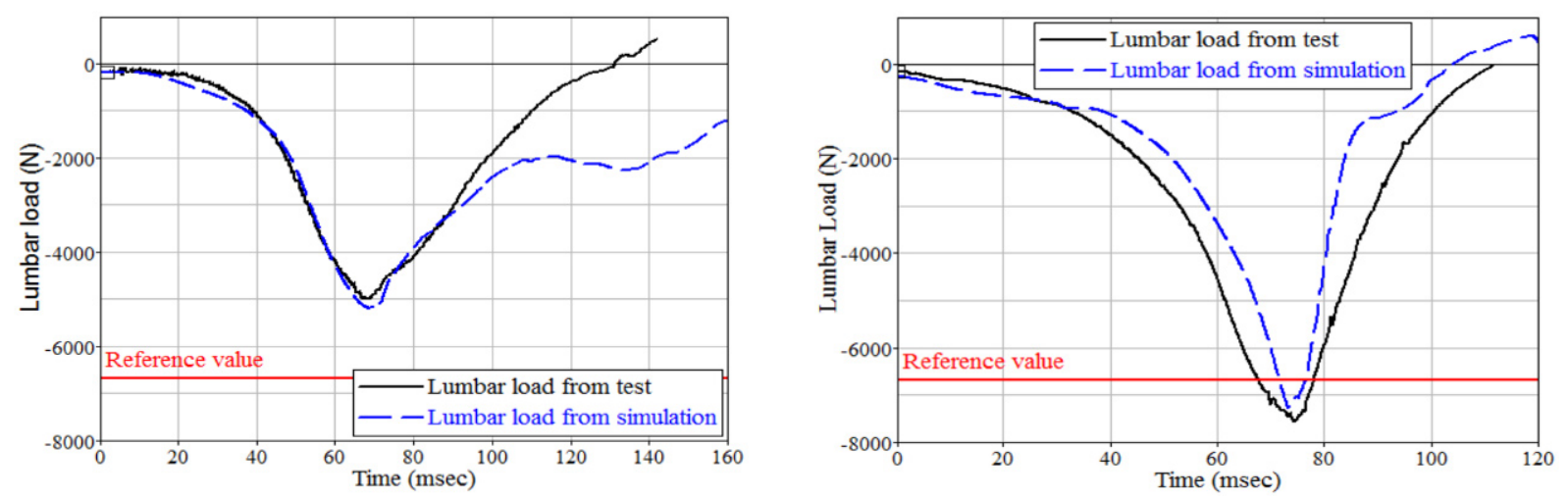

Figure 10. Comparison of occupant-sustained lumbar load for bare iron seat under FAR 25 (left) and for a 5-in-thick industry cushion under FAR 23 (right) from this study and sled test [18].
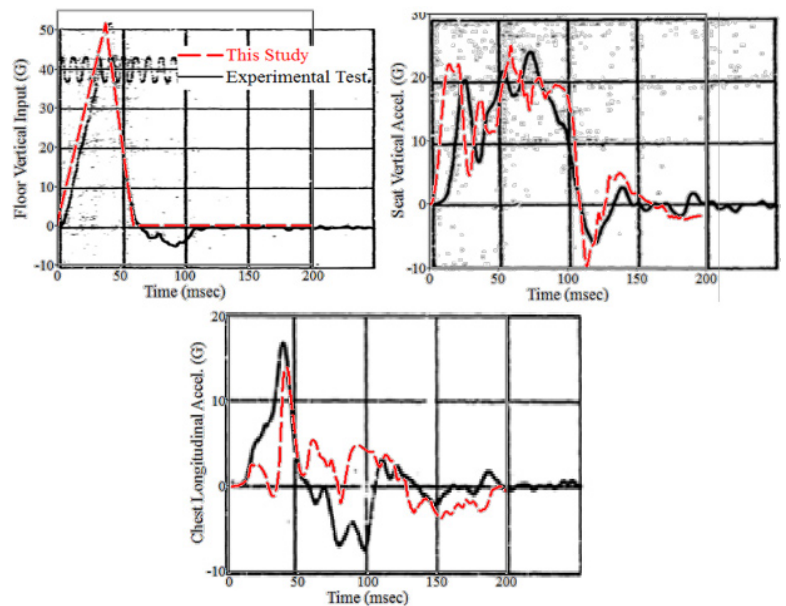

Figure 11. Comparison of results from this study with results from experimental study for a $95^{\text {th }}$-percentile occupant on an energy-absorbing seat [27].

related to different dummy models utilized in the test and in this study.

To have the energy absorber system validated further, the system of a $95^{\text {th }}$-percentile male aviator on a seat with an energy absorber was tested under a vertical acceleration of $51.6 \mathrm{G}$, rise time of $0.027 \mathrm{sec}$, velocity change of $14.3 \mathrm{~m} / \mathrm{sec}$ (47 ft/sec), and load-limiting force of $25310 \mathrm{~N}$ (5696 lbf). Results were then compared with the experimental test [27]. To correlate the results from this study with the published data, the mass of the seat system was set to be $68.9 \mathrm{~kg}$ (152 lb); hence, the total movable mass of $144 \mathrm{~kg}$ (318 lb) was considered.

Results from the simulation show a seat stroke of $32.7 \mathrm{~cm}$ (12.9 in), which is comparable to $32.8 \mathrm{~cm}$ (12.9 in) from the test. This test was conducted in a low environmental temperature, which simulated the cushion and dummy stiff-

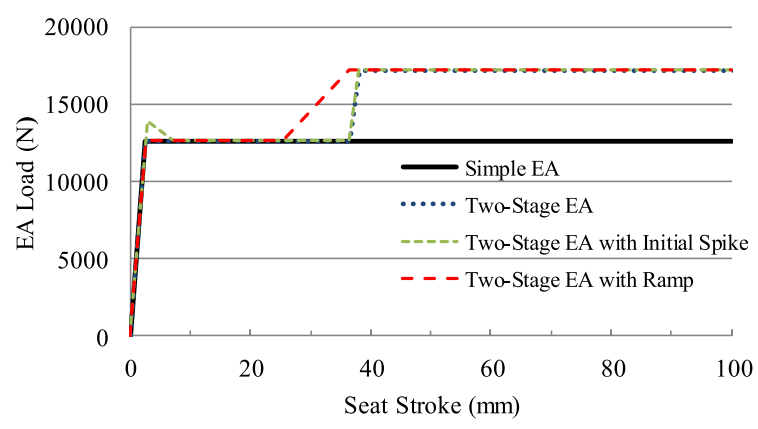

Figure 12. Load-limiting curves for energy absorber.

ness characteristics as almost rigid characteristics. This reduced the effect of pelvic and cushion compliances and, hence resulted in lower pelvic deceleration peak compared to the simulation results, as shown in Figure 11. On the other hand, the energy absorber in the test was not as ideal as in the simulation, which in turn caused some differences in results between the test and the simulation. Overall, the results were within $\pm 10 \%$ of each other, and hence, good confidence was obtained for the model validity.

\subsection{Results from Design Iterations (Paramet- ric Study)}

The seat energy absorber was subjected to a parametric study to design an efficient energy-absorbing system to minimize the occupant injury level while minimizing the seat stroke. The $50^{\text {th }}$-percentile FAA ATD model on a seat with a moveable mass of $27.2 \mathrm{~kg}$ (60 lb), shown in Figure 8, was subjected to the different seat energyabsorber systems, as shown in Figure 12. This figure identifies four different load-limit cases: simple EA, twophase EA, two-phase EA with initial spike, and two-phase 


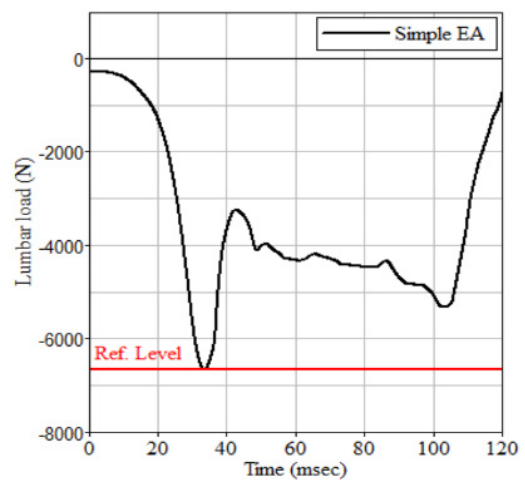

(a)

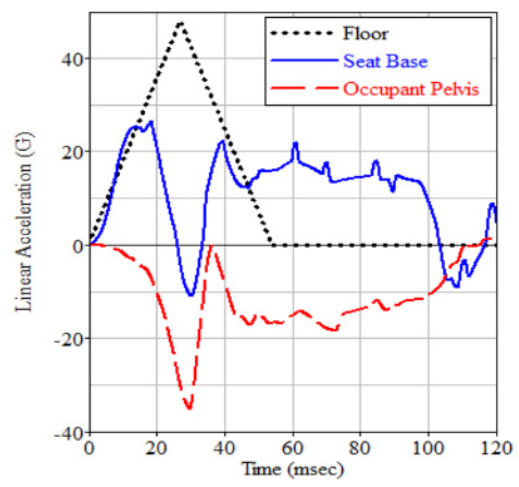

(c)

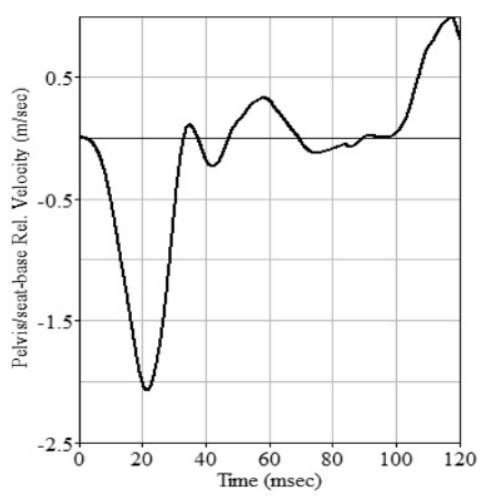

(b)

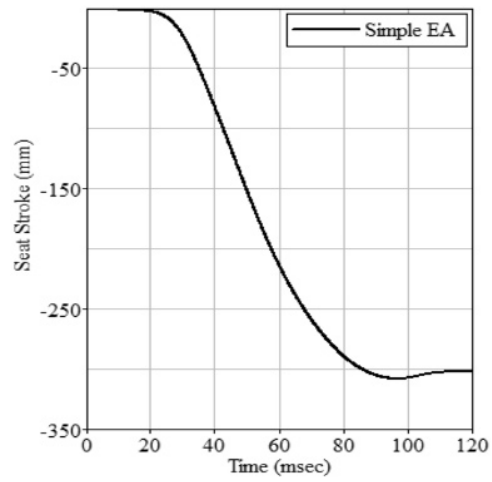

(d)

Figure 13. Occupant lumbar load, seat-base acceleration, seat/occupant relative velocity, and seat stroking curve for a simple load limiter.

EA with ramp. Figure 13(a) shows lumbar load history from the MADYMO model for a seat implemented with a one-stage load limiter of 14.5 G $(12640 \mathrm{~N})$. The relative velocity built up between the pelvis and seat bucket is also depicted in Figure 13(b). Results show that after the first spike in the lumbar load due to impact between the pelvis and seat pan, it is reduced to a relatively small value due to the small rebound. Then, the average lumbar load takes approximately the linear dynamic load value $(4850 \mathrm{~N})$ for a period of time and is gradually reduced to zero. The seat base and pelvis vertical accelerations along with airframe acceleration are plotted in Figure 13(c). Figure 13(d) shows the seat stroke for the case of the simple load-limiter energy absorber.

Simulation results for a two-stage load limiter are depicted in Figure 14. The load limiter is designed to give a relative velocity of zero at the end of the first and onset of the second step of the load limiter. The value of the second peak load is set to have a lumbar load below that of the first overshoot value, which is in the body tolerable range. Since the area under the load-deflection of the energy absorber is equal to the energy absorbed by the system, it is obvious that more energy is absorbed in the two-stage load limiter compared to that of the one-stage load limiter. Hence, the stroke in the two-stage load limiter would be less than that of the one-stage load limiter, which is shown in Figure 15. After a few iterations, to find the force level at the second stage of the energy-absorbing system, the load level was set to $15300 \mathrm{~N}(17.5 \mathrm{G})$.

Figure 15 shows results for the initially spiked load limiter as mentioned by Carr and Phillips [26]. For this purpose, the same two-stage load limiter, as shown in Figure 12, was used with an initial spike of about $10 \%$ during the first stage. Results for the two-stage energy absorber with ramp between stages are shown in Figure 16. A comparison of the lumbar loads for energy absorbers with different load limiter curves is depicted in Figure 17.

\section{Discussion}

A mathematical model was utilized to predict the sustained lumbar load when subjected to the vertical dynamic test conditions according to MIL-S-58095 for civil rotorcraft. 


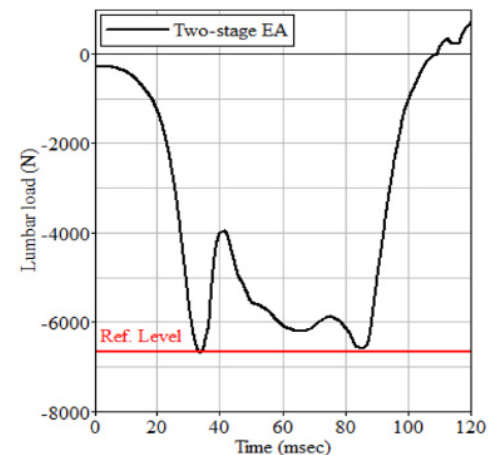

(a)

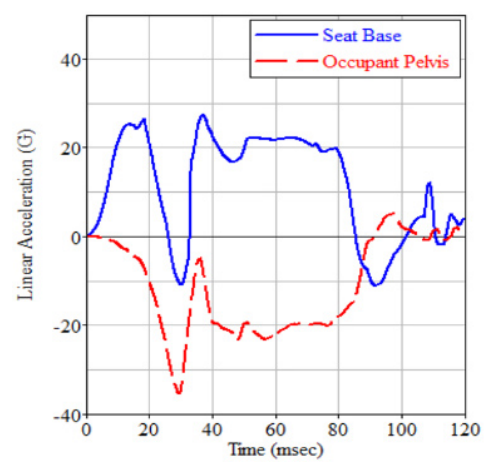

(c)

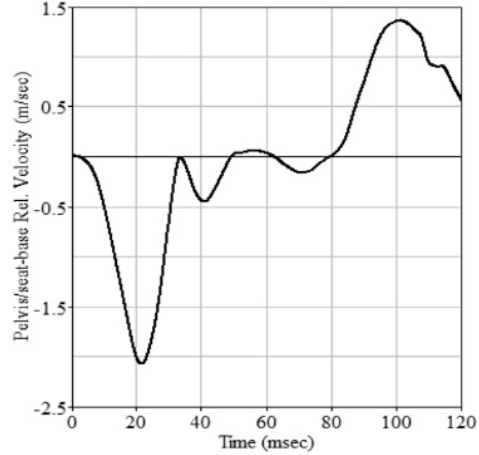

(b)

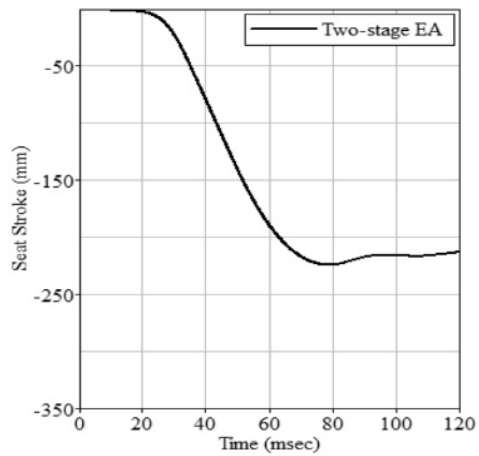

(d)

Figure 14. Occupant lumbar load, seat-base acceleration, seat/occupant relative velocity, and seat stroking curve for a two-stage load limiter.

The relative displacement and velocity of occupants with respect to the seat pan were also monitored. The model was validated with experimental dynamic sled tests as well as published data.

The two-stage VLEA profile, recommended in this study, uses a constant load displacement between stage one and stage two. The magnitude of the load-displacement is subject to change, based on different-size occupants and seat weights. For the first stage, the suggested startingpoint stroking load of $12650 \mathrm{~N}$, based on a $50^{\text {th }}$-percentile occupant weight and a movable seat mass of $60 \mathrm{lb}$, is equal to a load factor of $14.5 \mathrm{G}$. For the second stage of the aforementioned weight conditions, the suggested starting-point stroking load of $17200 \mathrm{~N}$, equal to a load factor of $20 \mathrm{G}$, was set to keep the maximum lumbar load in the human tolerable limits. The simulation indicates the second stage should "kick in" after one in $(2.5 \mathrm{~cm})$ of stroke, which strongly depends on the seat cushion properties and thickness. Utilizing the modified two-stage energy absorber, the stroke needed for the same level of occupant injury would be reduced. For the recommended two-stage EA, the stroke is reduced by more than 3 in $(7.5 \mathrm{~cm})$, as shown in Figures 13 to 16 . In another word, with the same stroke designed for a specific seat, the occupant lumbar spine injury level would be significantly attenuated.

At least three variables are used to examine each specific seat energy absorber. The first is the stage-one load limit value, which is the load limit based on load factor and the effective movable mass of the seat occupant. The second is the stage-two load limit value, which is the load level that does not create lumbar load more than that of the first peak. The third is the starting point for the stage-two load limit value, which depends on the relative velocity built up at stage one and the contact characteristics between the seat and the occupant's pelvis. The design of the energy absorber is such that it keeps the lumbar load within the tolerable limit while using the maximum energy-absorbing capability of the seat system and minimizing the seat stroke.

The second stage can be a step load input (simplest design) or can be ramped if a significant performance benefit is expected. The simulation indicates a negligible improvement for a ramped load limit EA. The ramp function for the load limiter indicates that the two humps of lumbar load can merge together at its maximum level. 


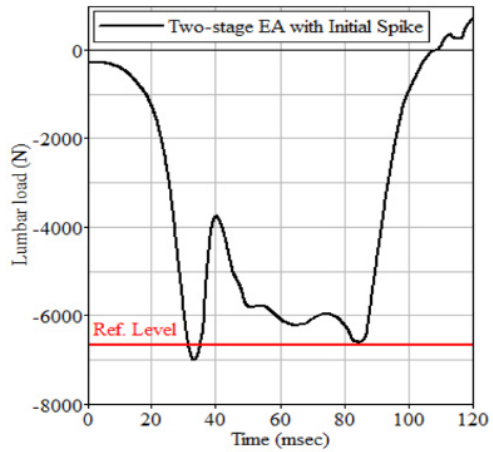

(a)

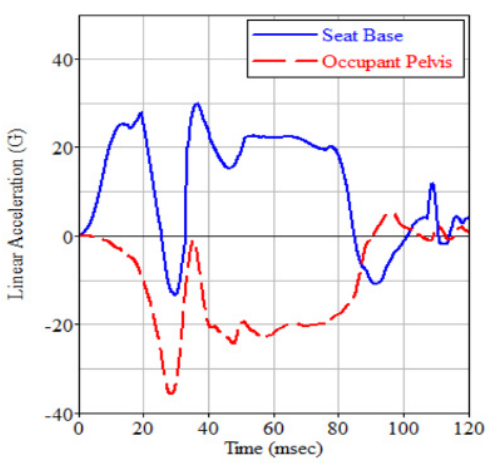

(c)

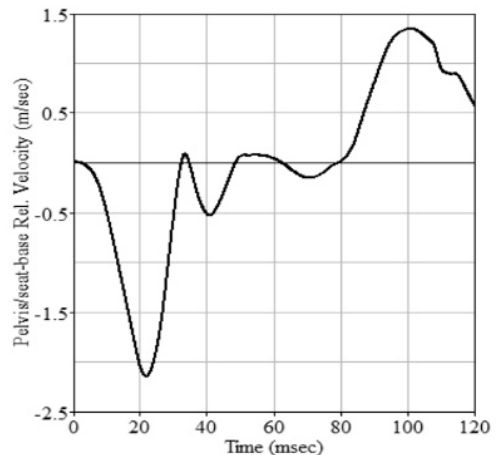

(b)

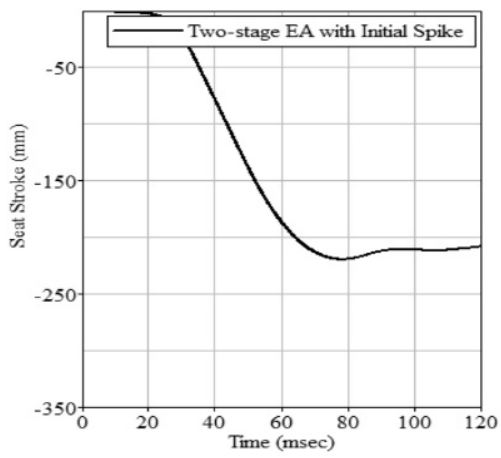

(d)

Figure 15. Occupant lumbar load, seat-base acceleration, seat/occupant relative velocity, and seat stroking curve for a two-stage load limiter with initial spike.

The recommended two-stage load-displacement profile allows the body to be decelerated at a higher average load. Since the maximum load in the spine typically results from dynamic overshoot, minimizing the overshoot allowed the average load to be raised while keeping the spine load within human tolerance limits.

As an inevitable fact, any contact of the occupant's arm with other body parts or seat system at the onset of the impulse changes the lumbar load peak significantly as observed from simulations. The arm support acts like a short cut for the load to be transferred to the upper body and subtracts the portion of the inertial force of the arm from the lumbar load. This indicates a need for more detail in describing the test requirement for occupant configuration as well as seat and cushion system.

It was also observed that unlike what has been suggested in some previous studies, any initial spike at loaddisplacement characteristics of the energy absorber helps in reducing neither the lumbar load nor the absorbed energy by the system. In contrast, since the load path starts with the impact with an occupant's pelvis, any initial increase in the load-limiting level increases the lumbar load while not significantly helping the stroke of the seat.

\section{Conclusion}

In this study, a mathematical model was first developed based on the kinematics of a rotorcraft seat and occupant for a one-stage load limiter at different load factors. The computational model was then further developed, and a two-stage energy-absorber system for a military and civil rotorcraft crew seat was implemented to minimize the seat stroke when subjected to vertical dynamic test conditions according to MIL-S-58095. The relative displacement and velocity of the occupant with respect to the seat pan were monitored for different energy-absorber system designs. The models were validated with experimental dynamic sled tests as well as published data.

Results from this study indicate that by utilizing the proposed two-stage energy absorber, while keeping the occupant lumbar load below the human tolerable limit, the seat stroke requirement could be significantly attenuated. It was observed that the seat cushion thickness significantly influenced the lumbar load overshoot at certain load-limit factors. This study also concludes that depending on the cushion thickness, the load limit must be set at a load factor considerably below the tolerable level in order to 


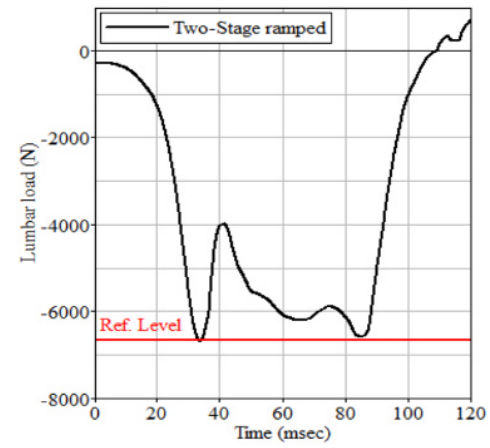

(a)

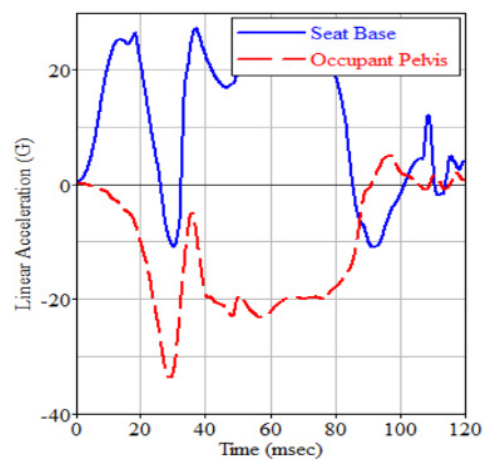

(c)

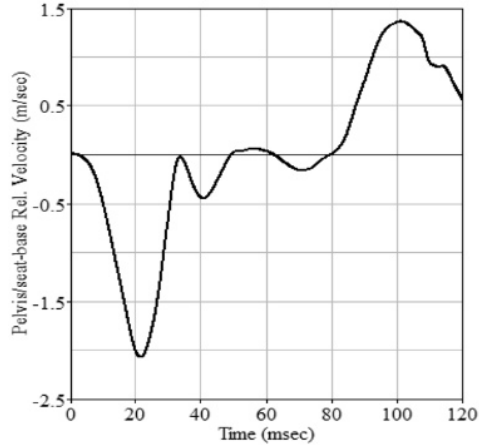

(b)

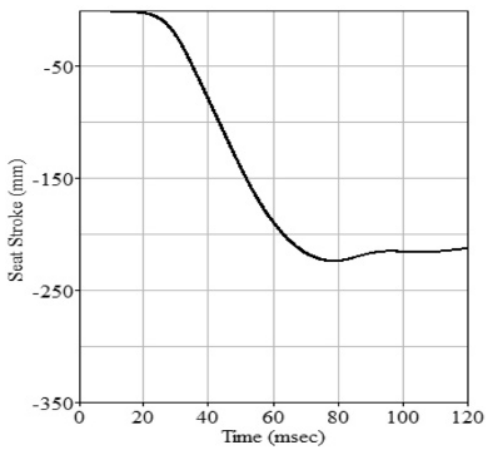

(d)

Figure 16. Occupant lumbar load, seat-base acceleration, seat/occupant relative velocity, and seat stroking curve for a two-stage load limiter with ramp.

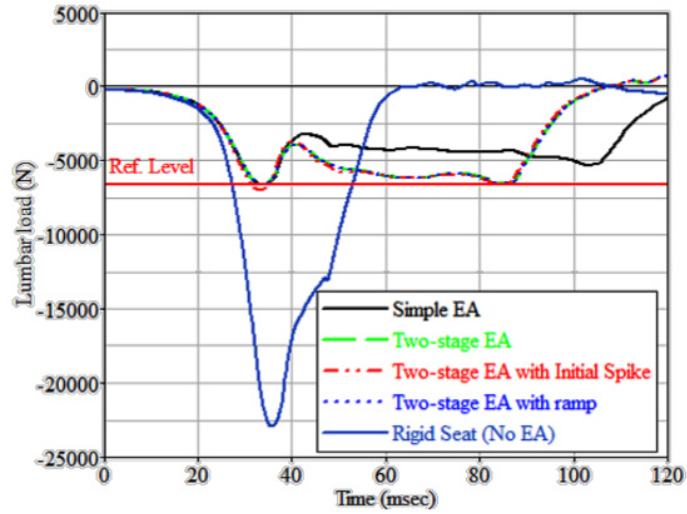

Figure 17. Comparison of occupant lumbar load for different load limiters.

limit the occupant response to a tolerable level, particularly for seats with high movable mass. The larger the movable seat mass, the higher the impact impulse to the occupant lumbar, and the lower the required load-limit factor. The load factor of $14.5 \mathrm{G}$ for a $50^{\text {th }}$-percentile male aviator and a given seat mass leads to a higher lumbar load and smaller seat stroke for a lighter effective mass of seat and occupant (i.e., $5^{\text {th }}$-percentile aviator) and a lower lumbar load and high seat stroke for a heavier effective mass of seat and occupant (i.e., $95^{\text {th }}$-percentile aviator). For any occupant and seat mass, the recommended twostage load-limiter design demonstrated an improvement in seat stroke. This improvement was shown to be about $25 \%$ for a $50^{\text {th }}$-percentile aviator with a light moveable seat mass.

The methodology and mathematical models developed in this study can be utilized in the design of energy-absorbing systems for seats. The results, however, indicate the need for further experimental testing to define the accurate load-limit factor, independent of environmental and system variables and based on human tolerable limits.

\section{References}

[1] McKenna J.T., NTSB Probes Part 135, Airline Safety Levels, Aviation Week and Space Technology, Vol. 140 (25), 32, 1994 
[2] Hughes D., Safety Group Highlights CFIT Risk for Regionals, Aviation Week and Space Technology, Vol. 140, 46-51, 1994

[3] Phillips E., NTSB: Regional's Need Higher Standards, Aviation Week and Space Technology, Vol. 144 (23), 72, 1996

[4] Desjardins S.P., The Evolution of Energy Absorption Systems for Crashworthy Helicopter Seats, The Journal of the American Helicopter Society, Vol. 51 (2), 150-163, 2006

[5] Hooper S.J., Ellis, D.R., Aviation Safety and Crashworthy Seat Design, International Journal of Crashworthiness, Vol. 2 (1), 39-54, 1996

[6] Chandler R.F., Human Injury Criteria Relative to Civil Aircraft Seat and Restraint Systems, SAE Paper 851847, Society of Automotive Engineers, Warrendale, PA, 1985

[7] Shanahan D.F., Shanahan M. O., Injury in U.S. Army Helicopter Crashes, October 1979-September 1985, J. Trauma, Vol. 29 (4), 415-22, 1989

[8] Title 14 Code of Federal Regulations, Part 23; Airworthiness Standards: Normal, Utility, Acrobatic, AND Commuter Category Airplanes, Amendment 23-39, Section 23.562, published in the Federal Register, 1988

[9] Title 14 Code of Federal Regulations, Part 25; Airworthiness Standards: Transport Category Airplanes, Amendment 25-64, Section 25.562, published in the Federal Register, 1988

[10] Title 14 Code of Federal Regulations, Part 27; Airworthiness Standards: Normal Category Rotorcraft, Amendment 25-64, Section 27.562, 1989

[11] Military Specification, MIL-S-58095A (AV), Seat System: General Specifications for Crashworthy, NonEjection, Aircrew, Department of Defense, Washington, DC, 1988

[12] Aircraft Crash Survival Design Guide Volume IV Aircraft Seats, Restraints, Litters, and Cockpit/Cabin Delethalization, Aviation Applied Technology Directorate, USAAVSCOM TR 89-D-22D, U.S. Army Aviation Research and Technology Activity (AVSCOM), Fort Eustis, VA 23604, 1989

[13] Payne P.R., Injury Potential of Ejection Seat Cushions, J. Aircraft, Vol. 6, 273-278, 1969

[14] Stech S. J., Payne P. R., Dynamic Models of the Human Body, Aerospace Medical Research Laboratory, Wright Patterson Air Force Base, Ohio, USA, 1969

[15] Flores P., Ambrosio J., Revolute Joints with Clearance in Multibody Systems, Computers and Structures, Special Issue: Computational Mechanics in Portugal, Vol. 82 (17-18), 1359-1369, 2004

[16] Beheshti H.K., Lankarani H.M., A Simplified Test Methodology for Crashworthiness Evaluation of Air- craft Seat Cushions, International Journal of Crashworthiness, Vol. 11 (1), 27-35, 2006

[17] ID\&M Technical Council, Development of a Seat Cushion Replacement Component Test Method, Report No. C-GEN-3433B-1, AGATE, Hampton, VA, 2004

[18] Lankarani H. M., Beheshti H. K., Aircraft Seat Cushion Replacement Program, FAA Airworthiness, Assurance Center of Excellence (AACC), Final Report DOT/FAA/AR-00-45, Wichita State University, KS, USA, 2004

[19] Williams M. S., Fasanella E. L., Results from Tests of Three Prototype General Aviation Seats, NASA Technical Memorandum 84533, NASA Langley Research Center, Hampton, VA 23665, 1982

[20] Lankarani H.M., Ng C.C., Alternative Design of Energy Absorbing Seat Legs for Commuter Aircraft Seats, Society of Automotive Engineers, Corporate and Regional Aviation Meeting and Exposition, Paper No. 971458, Wichita, KS, 1997

[21] Underhill B., McCullough B., An Energy Absorbing Seat Design for Light Aircraft, Piper Aircraft Corporation, SAE Paper No. 720322, Society of Automotive Engineers, Inc., New York, 1972

[22] Coltman J. W., Van Ingen,C., Smith K., Crashworthy Crew Seat Limit Load Optimization Through Dynamic Testing, Crashworthy Design of Rotorcraft Atlanta: Georgia Institute of Technology Center of Excellence for Rotary-Wing Aircraft Technology, 1986

[23] Coltman J. W., Design and Test Criteria for Increased Energy-Absorbing Seat Effectiveness, Final Report, Simula Inc., USAAVRADCOM TR-82-C-42, U. S. Army Applied Technology Laboratory, U. S. Army Research and Technology Laboratories (AVRADCOM), Fort Eustis, VA, 1993

[24] Eiband A. M., Human Tolerance to Rapidly Applied Accelerations: A Summary of the Literature, NASA Memorandum 5-19-59E, NASA, Washington, DC, 1959

[25] Shanahan D. F., Black Hawk Crew Seats: A Comparison of Two Designs, Fort Rucker, AL: U.S. Army Aeromedical Research Laboratory, LR 92-1-4-1, 1991

[26] Carr R. W., Phillips N. S., Definition of Design Criteria for Energy Absorption Systems, Beta Industries Incorporated, Report No. NADC-AC-7007, Naval Air Development Center, Warminster, Pennsylvania, AD 871040, 1970

[27] Desjardins S. P., Harrison H. D., The Design, Fabrication, and Testing of an Integrally Armored Crashworthy Crew Seat, USAAMRDL Technical Report 71-54, U.S. Army Air Mobility Research and Development Laboratory Fort EUSTIS, Virginia, 1972

[28] Gilardi G., Sharf I., Literature Survey of Contact Dynamics Modeling, Mech. Mach. Theor., Vol. 37, 12131239,2002 
[29] Goldsmith W., Impact: The Theory and Physical Behavior of Colliding Solids, Edward Arnold Publisher Ltd, London, 1960

[30] Military Specification - MIL S-85510 (AS), Military Specification, General Specification for Seats, Helicopter Cabin, Crashworthy, Department of Defense, Washington, DC, 20301, 1981

[31] Aerospace Standard, SAE, AS8049A, Performance Standard for Seats in Civil Rotorcraft, Transport Aircraft, and General Aviation, issued 1990 and revised 1997
[32] Title 49 Code of Federal Regulations, Part 572, Subpart B, Anthropomorphic Test Dummy, U.S. Government, Printing Office, Washington DC, revised 1978

[33] Kitazaki S., Griffin M.J., Resonance Behavior of the Seated Human Body and Effects of Posture, J. Biomech., Vol. 31, 143-149, 1998

[34] MADYMO Theory Manual, version 6.1, TNO Company, The Netherlands, 2003

[35] Military Standard, MIL-STD-1333A, Aircrew Station Geometry for Military Aircraft, Department of Defense, Washington, DC 20301, 1977 